\title{
SURGICAL MANAGEMENT OF CONSTRICTIVE PERICARDITIS
}

\author{
'M. TETTEY, L. SEREBOE, E. ANITEYE, F. EDWIN, D. KOTEI, M. TAMATEY, K. ENTSUA- \\ MENSAH and K. FRIMPONG-BOATENG \\ National Cardiothoracic Centre, Korle Bu Teaching Hospital, P.O. Box 77, Korle Bu, Ghana
}

\begin{abstract}
SUMMARY
Background: Constrictive pericarditis is a disease characterized by marked thickening and dense scarring of the pericardium with pericardial sac obliteration, or calcification of the pericardium. Without treatment this disease is characterized by high morbidity and mortality.

Objective: To review the surgical management of constructive pericarditis and the post operative challenges. Methods: Eleven patients who had pericardiectomy for constructive pericarditis between 2000 and 2005 were studied. Data was obtained from the operating theatre register, histopathological reports and patient's case notes.

Results: The mean age was 33 years with a range of 14 to 53 years. There were seven males (63.6\%) and four females $(36.4 \%)$. Seven $(63.6 \%)$ out of the eleven patients operated were treated for pulmonary tuberculosis. The cause of pericardial constriction in four patients (36.4\%) was undetermined. Follow up period was between 4-59 months. The mean follow up was 17.5 months. Seven patients (63.6\%) were off diuretics and had no exercise intolerance. Patients were classified using the New York Heart Association (NYHA) n (NYHA) functional and therapeutic classification in class I-V. Two patients preoperatively in class III are now in class I after surgery on low dose diuretics. One patient who had calcific constrictive pericarditis and came in class III was now in class II with diuretics after 3 years of follow up. There was no postoperative mortality. One patient was lost to follow up.

Conclusion: Pericardiectomy is a useful procedure for constrictive pericarditis and was beneficial to all the patients in this study with an improvement in their functional capacity. Intensive peri-operative monitoring and management reduced morbidity and mortality.
\end{abstract}

Keywords: Constrictive pericarditis, pericardiectomy, pericardium

\section{INTRODUCTION}

Constrictive pericarditis is a chronic inflammatory process that leads to progressive pericardial fibrosis encasing the heart in a thickened fibrotic pericardium. This causes impaired diastolic cardiac function leading to heart failure manifested as systemic without pulmonary congestion. ${ }^{1}$ It is an uncommon condition with the largest series reported from the Mayo Clinic of 366 patients extending over 60 years. ${ }^{2}$ Medical treatment of these patients has not been successful in many centers. Observational studies and case reports suggest that in most instances constrictive pericarditis without surgical intervention causes progression of symptoms and early death. ${ }^{1}$ The purpose of this report is to review the surgical management of constructive pericarditis and the post operative morbidity and mortality.

\section{PATIENTS AND METHODS}

\section{Patients Selection}

Eleven consecutive patients who underwent pericardiectomy for constrictive pericarditis between 2000 and 2004 at the National Cardio-thoracic Centre, Accra Ghana were selected. The data were collected retrospectively from the operating theatre register, histopathological reports and the patient's case notes. The diagnosis of constrictive pericarditis was made on the basis of clinical, diagnostic, surgical and pathological criteria. Information was integrated from clinical and diagnostic modalities (electrocardiogram, chest X-ray, echocardiogram). Surgical and pathological findings were subsequently reviewed to confirm the preoperative diagnosis.

\section{Follow-up}

All patients were reviewed two weeks after discharge from the hospital. Their clinical conditions were assessed and any complications following discharged were documented. Similar reviews were carried out monthly for a further two to three months. Subsequent reviews were scheduled depending on the clinical status of the patient.

\section{RESULTS}

The average age of the patients was 33 years with range of $14-53$ years. Four patients (36.4\%) were females and seven (63.6\%) were males. tuberculosis accounted for $63.6 \%$ of the cases. Calcific constrictive pericarditis was diagnosed in four patients (36.4\%) who had treatment for constrictive pericarditis. The cause of pericardial constriction in the rest of the cases

* Author for correspondence 
was unknown. Three (27.3\%) of the cases were in atrial fibrillation before and after the operation. patient was lost to follow up two years after the surgery.

Table 1 Pre and Post operative characteristics of patients who underwent pericardiectomy

\begin{tabular}{|c|c|c|c|c|c|c|c|c|c|c|}
\hline $\begin{array}{c}\text { Case } \\
\text { No }\end{array}$ & Age & Sex & $\begin{array}{l}\text { Aeti- } \\
\text { ology }\end{array}$ & $\begin{array}{l}\text { Cardiac } \\
\text { rhythm }\end{array}$ & $\begin{array}{c}\text { EF } \\
\text { perop }\end{array}$ & $\begin{array}{c}\text { NYHA } \\
\text { preop }\end{array}$ & $\begin{array}{l}\text { NYHA } \\
\text { postop }\end{array}$ & $\begin{array}{c}\text { Ionotrop- } \\
\text { ic sup- } \\
\text { port } \\
\text { postop } \\
\end{array}$ & $\begin{array}{l}\text { Ventilato- } \\
\text { ry support } \\
\text { postop }\end{array}$ & $\begin{array}{l}\text { Number } \\
\text { of days } \\
\text { on ad- } \\
\text { mission }\end{array}$ \\
\hline 1 & 16 & $F$ & TB & SR & 66 & II & - & - & - & 9 \\
\hline 2 & 35 & $\mathrm{M}$ & TB & SR & 68 & II & - & YES & YES & 14 \\
\hline 3 & 14 & $\mathrm{~F}$ & - & SR & 64 & III & - & - & - & 13 \\
\hline 4 & 53 & F & TB & SR & 65 & III & II & YES & YES & 10 \\
\hline 5 & 27 & $\mathrm{M}$ & TB & SR & 64 & III & - & YES & - & 14 \\
\hline 6 & 24 & $\mathrm{M}$ & TB & SR & 76 & III & I & YES & YES & 13 \\
\hline 7 & 47 & $\mathrm{~F}$ & - & SR & 66 & III & I & YES & - & 14 \\
\hline 8 & 37 & $\mathrm{M}$ & - & SR & 67 & II & - & - & - & 10 \\
\hline 9 & 47 & $\mathrm{M}$ & TB & SR & 65 & III & - & - & - & 11 \\
\hline 10 & 18 & $\mathrm{M}$ & - & SR & 68 & III & - & - & - & 12 \\
\hline 11 & 46 & $\mathrm{M}$ & TB & SR & 66 & III & - & YES & - & 14 \\
\hline
\end{tabular}

Preoperatively, eight patients (72.7\%) were in class III and three patients (27.3\%) in class II using the New York Heart Association (NYHA) functional and therapeutic classification. Postoperatively, six (54.5\%) and three patients (27.3\%) needed ionotropic and ventilatory support respectively. There was no perioperative mortality. Table 1 shows the pre and postoperative characteristics of patients who underwent pericardiectomy.

Seven out of the eleven patients were diagnosed with tuberculosis before surgery. Two patients were treated for pulmonary tuberculosis before presenting to the Centre. Tuberculous pericardial effusion was diagnosed in three patients after pericardial biopsy and had completed treatment before presenting with constrictive pericarditis. Two were put on treatment for tuberculous pericarditis empirically for three months before surgery was carried out and treatment was completed after surgery when diagnosis was confirmed by histopathological report. Four out of the seven patients diagnosed with tuberculosis had calcific constructive pericarditis.

\section{Surgical Technique}

Pericardiectomy, limited anteriorly to the left and the right phrenic nerves, was performed through a median sternotomy in the 11 cases. The resection of the pericardium extended from the right to the left phrenic nerves anteriorly. It was up to the great vessels superiorly and to the diaphragmatic surface and the inferior vena cava inferiorly. All the operations were performed without cardiopulmonary bypass. All patients had full cardiovascular monitoring including invasive blood pressure and central venous pressure monitoring. One

\section{DISCUSSION}

Resecting the pericardium for constrictive pericarditis dates back to 1828 when it was first suggested by De Lome. ${ }^{3}$ It remained for the German surgeon, Rehn in 1913 to resect a constricting pericardium through a left anterolateral thoracotomy with great improvement in his patient's condition. Subsequent successes were reported by Churchill in $1928 .^{3}$ Paul Wood in 1961 noted that only details had been added to the picture presented to the English speaking world by Paul Dudley White in his 1935 St. Cyres lecture. ${ }^{4}$

The surgical significance of the pericardium arises when cardiac filling is perturbed. When inflammation and scarring cause the pericardium to shrink and densely adhere to the surface of the heart, constrictive pericarditis is the consequence. ${ }^{5}$ Variants of constrictive pericarditis have been described. ${ }^{4}$ These are effusive constrictive pericarditis, occult constrictive pericarditis, localized constrictive pericarditis and transient constrictive pericarditis. ${ }^{4}$

A wide range of disease processes can result in the formation of a pericardial scar. In the developing world where tuberculosis is still common, it remains the major cause of constrictive pericarditis. In this study, tuberculosis accounted for $63.6 \%$ of the causes of pericardial constriction. In a study carried out in India, tuberculosis accounted for $40 \%$ of the cases. ${ }^{3}$ A similar result (39\%) was reported in another study in Gabon. ${ }^{6}$ Other causes of constrictive pericarditis common in developed countries are cardiac surgery, therapeutic irradiation of the mediastinum and trauma. ${ }^{3,45}$ The ae- 
tiology of constrictive pericarditis was idiopathic or viral in $46 \%$ of cases studied by Stefan et $\mathrm{al}^{1}$, and $61 \%$ in another study by Ashok et $\mathrm{al}^{7}$. In our study, the aetiology of constrictive pericarditis in $36 \%$ of the cases was undermined.

The clinical and diagnostic distinction between constrictive pericarditis and myocardial diseases especially the restrictive cardiomyopathies has often been difficult because haemodynamic behaviour of the two processes is similar. ${ }^{8}$ The diagnosis of patients in this study was made on the basis of clinical, diagnostic (electrocardiogram, chest $\mathrm{X}$ ray, echocardiography), surgical and pathological criteria. Additional diagnostic modalities used in other studies include computerized tomography scan, magnetic resonance imaging and myocardial biopsy. ${ }^{8-12}$

Constrictive pericarditis is a slowly progressive disease and a cause of heart failure. ${ }^{10}$ All the patients in this study were in NYHA functional classification class II and III. Studies carried out elsewhere had patients in class I and IV before surgery ${ }^{15}$. NYHA functional class IV among others was found to be a significant predictor of poor postoperative outcome. ${ }^{7,15}$ Delay in surgical treatment makes prognosis worse for patients. Medical management has not been helpful in the management of constrictive pericarditis. Surgical pericardiectomy is highly effective and potentially curative for the heart failure. ${ }^{10}$

Surgical management of constrictive pericarditis remains the only effective treatment for this potentially curable disease. ${ }^{3}$ Various approaches and techniques have been suggested. These include left anterolateral thoracotomy, median sternotomy, a ' $U$ ' incision with the base of the ' $U$ ' lying at the left sternal boarder (Harrington approach) and bilateral thoracotomy (Churchill). ${ }^{3,13}$ The Churchill and Harrington approaches are now of historical interest. Pericardiectomy is now routinely carried out through a median sternotomy or a left anteriolateral thoracotomy. At the National Cardiothoracic Centre, median sternotomy was used in all the cases. In this study, pericardiectomy limited anteriorly to the phrenic nerves resulted in $100 \%$ improvement in the functional status of our patients with no early or late mortality. Excellent survival was also reported after complete phrenic to phrenic pericardiectomy. ${ }^{1}$ Normalization of cardiac heamodynamics has been seen after decortication of the anterior surface of the ventricles from the atrioventricular groove on the right to the left phrenic nerve and the diaphragmatic surface. ${ }^{3}$

However, some studies have shown that radical pericardiectomy through median sternotomy give better results than the partial pericardiectomy in our study. In an article by Culliford et al, it was demonstrated that radical pericardiectomy was associated with excellent outcome. ${ }^{15}$ In another study by Chowdhury et al evaluating the hemodynamics of total versus partial pericardiectomy, it was found that total pericardiectomy confers significant advantage by providing superior haemodynamics that appear to be independent of the aetiology of constrictive pericarditis. Total pericardiectomy was also associated with lower perioperative morbidity and mortality. ${ }^{16}$ In spite of the improved haemodynamics and function with total pericardiectomy, our results showed a $100 \%$ improved functional status and no mortality over the period the cases were reviewed. Adequate removal of diseased pericardium over the right atrium, superior and inferior venae cavae relieves the systemic congestion and this contributed greatly to the post operative outcome in this study. Median sternotomy allows a more radical clearance of pericardium over the right atrium and venae vavae.

\section{CONCLUSION}

The results demonstrate that surgical management of constrictive pericarditis with prudent peri-operative management is safe and results in excellent improvement in cardiac functional capacity. The results of the study using partial pericardiectomy are comparable to other studies where radical or total pericardiectomy carried out.

\section{REFERENCES}

1. Bertog S C, Thambidorai S K, Parakh K, Schoenhagen P, Ozduran V, Houghtaling P L, Lytle B W, Blackstone E H, Luer M S, Klein A L. Constrictive Pericarditis: etiology and cause-specific survival after pericardiectomy. J Am Coll Cardiol, 2004;43: 1445-1452.

2. Ling L H, Oh J K, Schaff H V, Dannielson G K, Mahoney D W, Seward J B, Tajik J. Constrictive Pericarditis in the Modern Era Evolving Clinical Spectrum and Impact on Outcome after Pericardiectomy. Circulation 1999;100: 1380-1386.

3. Tiruvoipati R, Naik R D, Loubani M, Billa G N. Surgical approach for pericardiectomy: a comparative study between median sternotomy and left anterolateral thoracotomy. Interactive Cardiovascular and Thoracic Surgery. 2003;2:322-326.

4. Hancock E W. Differential diagnosis of restrictive cardiomyopathy and constrictive pericarditis. Heart 2001;86:343-349.

5. Cohn L H, Edmunds Jr H L. (eds.) Cardiac Surgery in the Adult. $2^{\text {nd }}$ Edition. 2003 Chapter 57 New York: McGraw-Hill,.

6. Ondo N'Dong F, Mbamendame F, Assapi M N, M'Bourou B, Rousselot M M, Diane C. Traite- 
ment chirurgical des pericarditis chroniques constrictives a Libreville. African Annals of Thoracic and Cardiovascular Surgery 2005;1(1):15-18.

7. Srivaastava A K, Ganjoo A K, Misra B, Chaterjee T, Kapoor A, Pandey C M. Subtotal Pericardiectomy Via Sternotomy for Constrictive Pericardidtis. Asian Cardiovasc Thorac Ann 2000;8:134-136.

8. Wang A, Bashore T M. Undercover and Overlooked. New England Journal of Medicine. 2004;351(10):1014-1019.

9. Ling L H, Oh J K, Breen J F, Schaff H V, Dannielson G K, Mahoney D W, Seward J B, Tajik J. Calcific Constrictive Pericarditis: Is it still with us? ANNALS 2000;32(6):444-450.

10. Wang Z J, Reddy G P, Gotway M B, Yeh B M, Hetts S W, Higgins C B. Computerised Tomography and Magnetic Resonance Imaging of pericardial disease. Radiograghics 2003;23:S167-S180.

11. Deepak R T, Edwards W D, Danielson G K, Scaff H V, Tajik A J, Tazelaar H D, Breen J F, Oh J K. Constrictive pericarditis in 26 Patients With Histologically Normal Pericardial Thickness. Circulation. 2003;108:1852-1858

12. Spray T L. Surgical Disorders of the Pericardium. In: Textbook of Surgery. David C Sabiston. (ed). $14^{\text {th }}$ edition. $W B$ Saunders Company. U.S.A. 1991; 1819.

13. McCaughan BC, Schaff H V, Piehler J M, Danielson G K, Orszulak T A, Puga F J, Pluth J R, Connolly D C, McGoon D C. Early and Late results of pericardiectomy for constrictive pericarditis. The Journal of Thoracic nd Cardiovascular Surgery. 1985;89:340-350.
14. Trotter M C, Chung K C, Ochsner J L, McFaddden P M. Pericardiectomy for pericardial Constriction. Am Surg 1996;62(4):304-307.

15. Culliford A T, Lipton M, Spencer F C. Operation for chronic constrictive pericarditis: Do the surgical approach and degree of pericardial resection influence the outcome significantly? The Annals of Thoracic Surgery. 1980;29:146-152.

16. Chowdhury U K, Subramanian G K, Kumar S, Airan B, Singh R, Talwar S, Sandeep S, Mishry P K, Pradeep K K, Sathia S, Venugopal P. Pericardiectomy for Constrictive Pericarditis: A Clinical Echocardiographic and Hemodynamic Evaluation of Two Surgical Techniques. Ann Thorac Surg 2006;81:522-529.

17. Benrhard M, Arsen D R. Practical aspects of the management of pericardial disease. Heart .2003;89:1096-1103.

18. Gregory M A, Whitton I D, Cameron E W. Myocardial ischaemia in constrictive pericarditis - a morphometric and electron microscopical study. Br. J. Exp. Pathology. 1984 June; 65(3) 365-376.

19. Schofield R S, Shoemaker S B, Ryerson E G, Cooper G R, Spotnitz W D. Left ventricular dysfunction after pericardiectomy for constrictive pericarditis. Ann Thorac Surg 2004;77:1449-1451.

20. Senni M, Redfield M M, Ling L H, Dannielson G K, Tajik A J, Oh J K. Left ventricular systolic and diastolic function after pericardiectomy in patients with constrictive pericardiectomy: Doppler echocardiographic findings and correlation with clinical status. J Am Coll Cardiol 1999;33(5):11821188. 